\title{
ПРИНЦИПЫ ФОРМИРОВАНИЯ ЭФФЕКТИВНЫХ ПРОЕКТОВ В ОБЛАСТИ ПОВЫШЕНИЯ ЭНЕРГОЭФФЕКТИВНОСТИ ДЕЯТЕЛЬНОСТИ ПРЕДПРИЯТИЯ
}

\author{
(c) 2020 Галиева Дарья Андреевна \\ Высшая инженерно-экономическая школа \\ Санкт-Петербургский политехнический университет Петра Великого (СПбПУ), \\ Россия, Санкт-Петербург \\ E-mail: daria.galieva@mail.ru \\ (c) 2020 Иванова Елена Гелиевна \\ кандидат технических наук, Высшей школы теоретической механики \\ Санкт-Петербургский политехнический университет Петра Великого (СПбПУ), \\ Россия, Санкт-Петербург \\ E-mail: ivanova_eg@spbstu.ru \\ (c) 2020 Конников Евгений Александрович \\ кандидат экономических наук, Высшая инженерно-экономическая школа \\ Санкт-Петербургский политехнический университет Петра Великого (СПбПУ), \\ Россия, Санкт-Петербург \\ E-mail: konnikov.evgeniy@gmail.com \\ (c) 2020 Конникова Ольга Анатольевна \\ кандидат экономических наук, кафедра маркетинга \\ Санкт-Петербургский государственный экономический университет (СПбГЭу), \\ Россия, Санкт-Петербург \\ E-mail: olga.a.konnikova@gmail.com
}

Одной из основных задач государства на данный момент является повышение энергетической эффективности экономики. Это обусловлено множеством факторов: высокий уровень энергоемкости, требование социально-экономического развития, модернизация экономики, необходимость повышения конкурентоспособности промышленности и улучшение состояния окружающей среды. В соответствии с установленной спецификой, целью исследования является разработка принципов формирования эффективных мероприятий по повышению энергоэффективности деятельности предприятия. В рамках достижения данной цели были исследованы мировые тенденции повышения энергетической эффективности, проанализированы успешно реализованные проекты мероприятий по повышению энергоэффективности и в завершении разработаны рекомендации по формированию проектов, повышающих показатели энергоэффективности деятельности предприятия.

Ключевые слова: энергоэффективность, энергосбережение, повышение эффективности, топливоиспользование.

Повышение энергоэффективности является одной из актуальных задач, так как это важное условие развития экономики страны и ее конкурентоспособности в современном мире. Результативность программ по повышению энергоэффективности определяют место страны в ряду экономически развитых стран и уровень жизни граждан. Уровень энергоемкости ВВП России в настоящее время снижается, но все равно в 2-3 раза превышает аналогичный показатель в развитых странах. Это негативно сказывается на экономике все страны, делая ее более затратной и неконкурентоспособной.

Основная цель энергосбережения, которая следует из его основного определения - реализация ряда комплексных мероприятий, направленных на сокращение использования энергетических ресурсов во всех отраслях. Для того, чтобы осуществить повышение энергоэффективности в целом в стране, необходимо включать в политику развития страны этапы планирования программ энергосбережения. Процесс энергосбережения должен стать приоритетным направлением энергетической политики, а ос- 
новными действиями должны быть разработка и модернизация программ повышения энергетической эффективности.

Проведем анализ мирового опыта реализации государственных программ в области повышения энергоэффективности и выделим основные тенденции. Рассмотрим опыт государств, которые лидируют среди стран мира в сфере энергоэффективности, а именно Великобритании, Германии и США.

Великобритания последние годы реализует «План перехода к низкоуглеродной экономике» (The Low Carbon Transition Plan). Данный план предусматривает увеличение использования альтернативных и возобновляемых источников энергии, развитие ветровых электростанций, развитие технологий получения электроэнергии с помощью морских волн и приливов, развитие сети станций для подзарядки электромобилей. Согласно «Плану перехода к низкоуглеродной экономике», к 2020 году Британия должна получать $40 \%$ всей электроэнергии из низкоуглеродных источников. Также, политика Великобритании стимулирует значительное количество инвестиций в энергоэффективность, прежде всего за счет программы «Обязательство энергетической компании» (The Energy Company Obligation). Данная государственная программа повышения энергоэффективности помогает домашним хозяйствам сократить потери энергии от собственности и привести к меньшему энергопотреблению. Также в соответствии с Директивой ЕС (2012/27/EU) Министерство Энергетики в Британии реализует «Схему энергосбережения» (The UK Energy Savings Opportunity Scheme (ESOS)). Данная обязательная схема оценки и эффективности энергопотребления применяется к крупным предприятиям, работающим в Соединенном Королевстве, и требует от организаций проводить каждые четыре года энергетический аудит. Программа предназначена для снижения энергопотребления, экономии затрат и сокращения выбросов углерода в бизнес-секторе. Таким образом, благодаря своему разнообразию государственных документов Великобритания стала лидером в разработке программ, направленных на повышение энергоэффективности не только промышленного сектора, но реализации программы по внедрению энергоэффективности для решения проблем здравоохранения и в социальных сфере.

В рамках направления «Энергоэффектив- ность» Германию можно считать одной из ведущих мировых держав. Основными федеральными программами в области энергосбережения и энергоэффективности на сегодняшний день в Германии являются:

1. «Energieeffizienz - Made in Germany». Данная федеральная программа предусматривает конкретные меры, направленные на энергосбережение и энергоэффективность в промышленности, строительстве и транспорте.

2. «Energie-und Klimaprogramm 2007». Предоставленный в данном документе комплекс мер направлен на эффективную защиту климата, сокращение выбросов в атмосферу парниковых газов.

3. «Energiekonzept der Bundesregierung 2010». В соответствии с энергетической концепцией 2010/2011 года федеральное правительство описало руководящие принципы экологически безопасного, надежного и доступного энергоснабжения и пути его достижения. Стратегия ориентирована до 2050 года и определяет основной приоритет развития- возобновляемая энергия (доля возобновляемых источников энергии в совокупном энергопотреблении к 2050 г.- не менее 80\%).

Таким образом, традиционные источники энергии заменяются возобновляемыми источниками энергии. Главная цель - ориентированная на рынок энергетическая политика. Также можно выделить такие приоритетные направления как развитие ветроэнергетики и солнечной энергетики и расширение программ финансирования и инвестирования частного капитала в развитие энергетики.

В США в 1992 году вступил в силу закон об энергетической политике (Energy Policy Act). Данный государственный акт Соединенных Штатов состоит из двадцати семи наименований, в которых подробно излагаются различные меры, направленные на уменьшение зависимости страны от импортируемой энергии, создание стимулов для использования чистой и возобновляемой энергии и содействие энергосбережению в зданиях. Также в США реализуется программа «Energy Star», главная цель которой стимулировать потребителей, производителей и промышленные предприятия внедрять энергоэффективные продукты и виды деятельности, тем самым экономить средства и защищать окружающую среду.

В соответствии с вышесказанным, можно 
выделить основные тенденции политики государства, направленных на повышение энергоэффективности: использование и развитие возобновляемых источников энергии; производство и реализация энергосберегающих приборов и оборудования для производителей; стимулирование потребителей к использованию энергосберегающих приборов и материалов. Стоит отметить, что политика многих государств имеет общую тенденцию к повышению энергоэффективности экономики в целом. Однако, энергетическая политика государства во многом определяется крупными представителями отрасли. Для целей определения вектора развития отечественной энергетической политики, с прикладной точки зрения, проведем анализ программ по повышению энергоэффективности деятельности предприятий на примере ПАО «ТГК-1». Компания является ведущим производителем электрической и тепловой энергии в Северно-Западном регионе России, также является второй в стране территориальной генерирующей компанией по величине установленной электрической мощности.

Стратегией компании является обновление основных фондов для обеспечения эффективной работы в новых условиях функционирования рынка электроэнергии и мощности. Данная стратегия подразумевает ответственное отношение к энергосбережению и повышению энергоэффективности процессов производства электрической и тепловой энергии.

Для крупной генерирующей компании ПАО «ТГК-1» в условиях увеличения тарифов и цен на энергоносители недопустимо их нерациональное и неэффективное использование. Одной из приоритетных задач для предприятия становится создание условий для повышения энергоэффективности использования энергетических ресурсов и оборудования.

Основной целью программ, реализованных на структурных подразделениях ПАО «ТГК-1», является снижение удельных расходов топлива на отпуск электрической и тепловой энергии, снижение расхода электроэнергии на собственные нужны при производстве электрической и тепловой энергии, снижение потерь тепловой энергии при передаче, рациональное использование водных ресурсов. Все это достигается за счет реализации мероприятий по повышению энергетической эффективности.

За 2019 год реализации мероприятий по со- вершенствованию производственных систем, направленных на решение такой основной проблемы, как снижение затрат на топливноэнергетические ресурсы (ТЭР), были предложены и осуществлены следующие действия: повышение эффективности расходования электрической энергии на собственные нужды (в том числе на теплофикационные установки) тепловых станций; комплекс организационнотехнических мероприятий, направленных на повышение эффективности топливоиспользования; комплекс организационно-технических мероприятий, направленных на повышение эффективности водопользования; мероприятие по оптимизации режимов работы ТЭЦ.

Основными направлениями оптимизации затрат реализуемых программ повышения операционной эффективности на ТЭЦ в 2019 году стали:

1. Повышение эффективности топливоиспользования.

2. Повышение эффективности расходов на собственные нужды.

3. Повышение эффективности водопользования.

4. Оптимизация режимов работы ТЭЦ.

В рамках повышения эффективности топливоиспользования были выполнены такие мероприятия, как снижение потерь с уходящими газами; очистка внутренних поверхностей нагрева теплообменного оборудования турбинного цеха; мероприятия по выявлению и устранению неплотностей газового тракта и пылесистем котлов; очистка трубной системы ПСГ-1 от отложений; оптимизация режима работ парового котла; монтаж резервного трубопровода; капитальный ремонт и другие.

В ходе повышения эффективности расходов на собственные нужны проведены мероприятия, направленные на снижение затрат электроэнергии на тягодутьевые механизмы, и замена светильников с лампами накаливания на светильники со светодиодными лампами. Для повышения эффективности водопользования на ТЭЦ были выполнены мероприятия по замене пропускающей арматуры на нижних точках энергетических котлов и мероприятия по переводу отопления теплиц с парового на водяное.

Проанализировав все реализуемые программы по повышению энергоэффективности на предприятии, можно сделать вывод о том, что в 2019 году наибольшее количество мероприятий 
было реализовано для повышения эффективности топливоиспользования. Это объясняется тем, что в большей степени эффективное топливоиспользование определяет надёжность и экономичность работы теплоэлектроцентрали, что в свою очередь влияет на надежность энергосбережения энергосистемы страны. В системе топливоиспользования существуют такие негативные факторы, как недопоставки и неритмичные поставки топлива, ухудшение качественных характеристик топлива, а также увеличение стоимости топливных ресурсов. В свою очередь в системе топливоиспользования все негативные факторы приводят к ухудшению техникоэкономических показателей ТЭЦ, ускоряют износ оборудования, вызывают ущербы, приводят к росту себестоимости и тарифов на электро- и теплоэнергию. В значительной мере эти явления сделали актуальным поиск решений по совершенствованию систем топливоиспользования и реализации отдельных эффективных мероприятий. От реализации мероприятий по данному направлению был получен колоссальный экономический эффект.

Следует отметить, что мероприятия по повышению энергетической эффективности на ТЭЦ имеют разную проблематику и разные действия, предлагаемые для решения описанных проблем. Выбор энергосберегающих проектов осуществляется на основе всестороннего и тщательного анализа на этапе разработки проекта. Все мероприятия, реализованные в 2019 году, являются для предприятия экономически эффективными и улучшают технико-экономические показатели.

Проведя подробный анализ мероприятий по повышению энергоэффективности на ТЭЦ на примере генерирующей компании, можно отметить следующую тенденцию. Основным реализованным направлением являются мероприятия, по повышению эффективности топливоиспользования. Нужно предположить, что данное направление развития является наиболее перспективным и повлечет за собой наибольший экономический эффект для генерирующей компании.

Стоит принять во внимание, что резервы компании были направлены на повышение одной группы показателей топливоиспользования и в полной мере были реализованы. Что ведет за собой проблему реализации дополнительных резервов на другие мероприятия по повышению энергоэффективности. Таким образом, следует выдвинуть гипотезу о том, что необходимо усилить направления, которые уже успешно реализуются на предприятиях и направить разработку программ повышения энергоэффективности на принципиально другие направления. Усиление разработки мероприятий, направленных на повышение уже успешно реализуемых мероприятий по повышению эффективности топливоиспользования и увеличение количества данных мероприятий позволит увеличить энергоэффективность текущей деятельности теплоэлектроцентралей. А следующий вектор развития будет заключаться в разработке качественно других мероприятий, которые будут рассматриваться как ряд инвестиционных проектов для повышения энергоэффективности, нацеленных в будущее. Помимо экономии топлива, можно реализовывать мероприятия по повышению энергоэффективности направленные на ремонты и сокращение потребления электроэнергии на собственные нужды. Также внедрение низкозатратных реконструктивных работ будет приносить значительный результат по повышению энергоэффективности действующего энергетического оборудования. Модернизация и внедрение новых технических решений позволит повысить технико-экономические показатели оборудования. Главными критерия для выбора энергоэффективных мероприятий станут срок окупаемости, затраты на реализацию и наибольшая экономия энергоресурсов и их стоимость. Таким образом, сформулированы основные принципы по формированию дальнейших проектов, направленных на повышение энергоэффективности на теплоэлектроцентралях:

1. Первый принцип основывается на формировании новых проектов подобно самым эффективным из уже реализованных мероприятий. Принцип заключается в масштабировании мероприятий с наибольшим экономическим эффектом на всех теплоэлектроцентралях. Это позволит обеспечить наибольшую отдачу от реализации мероприятий по повышению энергоэффективности. По данному критерию предлагается реализовывать мероприятия, направленные на повышение топливоиспользования, так как мероприятия данной направленности показывают высокие показатели экономического эффекта для предприятий.

2. Второй принции заключается в реализации проектов, качественно отличающихся от менее эффективных проведенных мероприятий. 
Такие проекты зададут новый вектор в развитии мероприятий, направленных на повышение энергоэффективности, и позволят развивать менее эффективные области на предприятиях.

Таким образом для анализируемого предприятия, запланированные мероприятия должны быть направлены на уменьшение расхода топлива за счет снижения потерь при генерации энергии или за счет повышению эффективности процесса генерации энергии, что в свою очередь может быть выполнено в процессе совершенствования технологий на ТЭЦ. Новый вектор развития зададут мероприятия, ориентированные на введение новых цифровых технологий, которые будут нацелены на формирование интеллектуальной выработки.

Принимая во внимание предложенную стратегию и опираясь на сформулированные принципы, были рекомендованы следующие мероприятия:

1. Проведение эксплуатационной химической промывки внутренних поверхностей нагрева котлов.

2. Интеграция интеллектуальной системы управления расходом энергии на вынужденные нужды.

Реализация мероприятия химической промывки внутренних поверхностей нагрева котла предлагается проводить с целью повышения теплопередачи теплообменных поверхностей, которая снижается из-за образований отложений на внутренних поверхностях нагрева в процессе эксплуатации котлов. Реализация данного мероприятия позволит восстановить технические показатели оборудования, повысить КПД котла и снизить количество потребляемого топлива.

Под очисткой парового котла химическим способом подразумевается реализация ряда мероприятий, направленных на удаление отложений и засоров с внутренних элементов с помощью растворов реагентов. Плюсом проведения очистки данным методом является возможность проводить мероприятие без демонтажа оборудования с помощью специальных насосных установок для удаления накипи с элементов парового котла путем непрерывной циркуляции, а после утилизации химических реагентов. Химическая очитка котлов должна проводить по необходимости и применение данного мероприятия своевременно. Таким образом, масштабирование данного мероприятия на все паровые котлы повлечет за собой не только сокращение количества используемого топлива, но и будет экономически эффективным для предприятия.

Затраты на проведение химической очистки одного котла включают в себя: доставку до места проведения промывки, очистку котла, выведение раствора, обработку полости котла, выдачу необходимой документации. Стоимость мероприятия рассчитывается исходя из мощности котлоагрегата. По данным компании, занимающийся обслуживаем оборудования в городе Санкт-Петербург затраты на проведение химической очистки одного котла мощностью от 1 мВт до 3 мВт ориентировочно составят составит 50 тыс. руб.

Актуальность реализации мероприятия «Интеграция интеллектуальной системы управления расходом энергии на собственные нужды» заключается в том, что вопрос энергетической эффективности работы оборудования для обеспечения собственных нужд на станциях не является первоочередным. Это обусловлено тем, что расход на собственные нужды включается в технологические потери. При разработке и интеграции интеллектуальной системы управления расхода энергии на собственные нужды необходимо рассмотреть целостный стратегический план по внедрению и модернизации теплоэлектроцентралей. Это позволит системно решить проблему и подойти к технико-экономическому обоснованию создания интеллектуальной системы с точки зрения эффективности модернизации энергосистемы в целом.

Преимуществами внедрения интеллектуальной системы управления расходами энергии являются повышение эффективности операционной деятельности, рациональное регулирование пиковых нагрузок с помощью интеллектуальных приборов учета, надежность сети, позволяющая функционировать оборудованию в полную силу его фактических возможности и снижения расходов энергоресурсов. Действия, направленные на внедрение такой системы, заключаются в установке измерительных приборов и устройств, включающие в себя smart-счетчики и smart-датчики. Устройства усовершенствованных автоматизированных информационноизмерительных систем будет работать в режиме реального времени и позволять оперативно управлять инфраструктурой на теплоэлектроцентралях. Ссылаясь на зарубежный опыт, можно предположить, что совершенствование интеллектуальной системы управления поможет 
снизить расходы энергии на СН на $30 \%$.

Рассмотрим расчет экономического эффекта от реализации мероприятия на примере «Автовской» ТЭЦ в городе Санкт-Петербург. На станции расход электроэнергии на собственные нужды составляет 15,8\% к общей выработке. Затраты на реализацию мероприятия будут включать в себя услуги специалистов по разработке данного мероприятия. Их основная деятельность будет направлена на организацию проекта, проектирование интеллектуальной системы, опытная и промышленная эксплуатация. Срок работы ориентировочно займет 10 месяцев. В среднем внедрение такого проекта специалистом, занимающимся разработкой интеллектуальных компьютерных систем и программах решений со знанием технических аспектов отрасли, будет стоить около 100 тыс. руб за месяц работы. Таким образом, общие затраты на создание данного мероприятия составят 1 млн.руб.

Таким образом, исходя из всех проведенных исследований, были разработаны рекомендации по формированию дальнейших проектов и сформулирован ряд принципов по разработке проектов для повышения энергоэффективности деятельности в будущем. Основное предложение для развития дальнейших проектов заключается в масштабировании самых эффективных мероприятий из уже реализованных и внедрение нового вектора развития проектов по повышению энергоэффективности, направленного на внедрение цифровых технологий в деятельность предприятий. В ходе дальнейшей работы было разработано и предложено два мероприятия по повышению эффективности деятельности предприятий. Значимость результатов исследования заключается в возможности использование разработанных принципов и мероприятий для внедрения на предприятия.

Подводя итог, следует отметить, что разработка программ, направленных на повышение энергоэффективности деятельности предприятия, является одним из главных критериев ее высокоэффективной работы и конкурентоспособности.

\section{Библиографический список}

1. Акулова Я. Н. Энергоэффективность как способ повышения конкурентоспособности экономики [Электронный ресурс] // Управление экономическими системами. Электронный научный журнал. 2015. № 78. URL: http://uecs.ru/uecs-78-782015/item/3614-2015-06-29-08-07-33. (дата обращения: 24.05.2020)

2. Энергоэффективная Германия вчера, сегодня, завтра // ЮНИДО в России. URL: http://www. unido-russia. ru/ archive/num3/art3_6.

3. Седаш Т. Н. Использование зарубежного опыта повышения энергоэффективности в российской экономике // Финансовая аналитика: проблемы и решения. 2013. № 9.

4. Зверев А. В. Энергоэффективность и энергосбережение: мировой опыт для России / А. В.Зверев.- М.: ИИЦ «Статистика России», 2011.-175 с.

5. Ван Ф., Новикова О.В.Управление энергоэффективностью - вклад в устойчивое развитие // В сборнике: Фундаментальные и прикладные исследования в области управления, экономики и торговли. Сборник трудов научно-практической и учебной конференции: в 3 частях. 2018. С. 312-315.

6. Маскова Ю.Р., Новикова О. В. Проблема мотивации участников процесса повышения энергоэффективности // В сборнике: Промышленный менеджмент, экономика и экология - 2017. Сборник материалов международной учебно-научной конференции. 2017. С. 64-68.

7. Ерастов А.Е., Новикова О. В. Федеральное субсидирование как драйвер инновационного развития регионов в области энергосбережения и энергоэффективности // В сборнике: Реструктуризация экономики России и промышленная политика. Труды научно-практической конференции с зарубежным участием. Под редакцией А. В.Бабкина. 2015. С. 102-106.

8. Кичигин О.Э., Родионов Д.Г.Институциональный аспект формирования стратегических ориентиров государственной энергетической политики на региональном уровне при реализации стратегии национальной экономической безопасности // Экономика и предпринимательство. 2017. № 10-2 (87). С. 394-399. 